\section{REVISTA CIENTÍFICA RURAL}

ISSN: $1413-8263 \quad 2525-6912$
Revista Técnico-Científica

\title{
JARDIM VERTICAL E HORTA COMO FERRAMENTA DE EDUCAÇÃO AMBIENTAL EM ESCOLA EM ITUIUTABA-MG
}

\begin{abstract}
Estevam Matheus Costa ${ }^{1}$, Humberto Ferreira Silva Mineu², Arali AparecidaCosta Araujo ${ }^{3}$, Matheus Vinicius Abadia Ventura ${ }^{4}$, Luciana Cristina de Oliveira Alves ${ }^{5}$, Felippe Bryan Costa ${ }^{6}$, Gabriel Ribeiro Mendes $^{7}$
\end{abstract}

Mestrando em Ciências Agrárias - Agronomia pelo Instituto Federal Goiano campus Rio Verde ${ }^{1}$, Docente no Instituto Federal do Triângulo Mineiro campus Ituiutaba ${ }^{2}$, Docente na Universidade do Estado de Minas Gerais unidade Ituiutaba ${ }^{3}$, Doutorando em Ciências Agrárias - Agronomia pelo Instituto Federal Goiano campus Rio Verde ${ }^{4}$. Especialista em Gestão Licenciamento e Auditoria Ambiental na Universidade Norte do Paraná ${ }^{5}$, Engenheiro Agrônomo pela Universidade do Estado de Minas Gerais ${ }^{6}$, Engenheiro Agrônomo pela Universidade do Estado de Minas Gerais ${ }^{7}$.

RESUMO: Este projeto teve como objetivo auxiliar na formação consciente de estudantes do ensino fundamental de uma escola pública no município de Ituiutaba, MG, por meio da implantação de jardim vertical e horta como ferramenta de educação ambiental. As oficinas foram realizadas em uma escola e o projeto foi dividido em quatro oficinas sendo a primeira oficina voltada para a questão dos resíduos sólidos e os males que estes causam para o meio ambiente e para os seres humanos. Na segunda oficina foram apresentados os grupos de plantas e os benefícios de sua utilização. Na terceira foram abordadas questões relacionadas à compostagem do lixo, sendo que no final desta, em uma das escolas, os alunos fizeram suas composteiras utilizando matéria orgânica da própria escola. $O$ conhecimento construído a partir deste projeto permite que a comunidade crie seus jardins verticais e hortas para uso próprio ou até mesmo com finalidade comercial, praticando o manejo adequado e respeitando o meio ambiente. É possível pontuar que o jardim vertical nas escolas também pode ser utilizado como ferramenta de educação aplicando conceitos da interdisciplinaridade e de atividades práticas a fim de melhorar o entendimento dos alunos sobre diferentes temas.

Palavras-chave: meio ambiente, compostagem, resíduos urbanos.

\section{VERTICAL GARDEN AND HORTA AS A TOOL FOR ENVIRONMENTAL EDUCATION IN SCHOOL IN ITUIUTABA-MG}

ABSTRACT: This project had the objective of assisting in the conscious formation of elementary school students in a public school in the municipality of Ituiutaba, MG, through the implementation of vertical garden and vegetable garden as an environmental education tool. The workshops were held at a school and the project was divided into four workshops and the first workshop focused on the issue of solid 
waste and the ills they cause to the environment and to humans. In the second workshop were presented the groups of plants and the benefits of their use. In the third, questions related to the composting of garbage were addressed, and at the end of this one, in the schools, the students made their composts using organic material from the school itself. The knowledge built from this project allows the community to create their vertical gardens and gardens for their own use or even for commercial purposes, practicing proper management and respecting the environment. It is possible to point out that the vertical garden in schools can also be used as an educational tool applying concepts of interdisciplinarity and practical activities in order to improve students' understanding of different themes.

Keywords: environment, composting, municipal waste.

\section{INTRODUÇÃO}

A escola tem um papel fundamental ao agregar conhecimento e formação cidadã aos seus alunos, contribuindo no seu desenvolvimento para viver em sociedade e replicar esse conhecimento para as pessoas do seu convívio. Sendo necessário a utilização de novas técnicas e/ou estratégias para chamar atenção dos estudantes, mostrando os impactos e os benefícios daquilo que buscar no ensino aprendizagem, tendo um ensino eficaz (FERREIRA, 2018).

Com uma população mundial cada vez maior, as áreas verdes naturais vêm sendo substituídas pelas cidades, grandes complexos industriais, lavouras e pastagens. Assim, o verde foi desaparecendo e sobraram algumas poucas áreas, como parques, praças e jardins para que a natureza pudesse se manifestar. Deste modo, torna-se importante aproveitar todo e qualquer espaço para prática do micropaisagismo como forma de ornamentar e até mesmo torná-los produtivos, trazendo o verde para mais perto do homem. $\mathrm{O}$ micro paisagismo pode ser definido como "o trabalho de remodelação da paisagem, criando jardins em terrenos com área inferior a (aproximadamente) 100 $\mathrm{m}^{2}$. Assim, incluem-se as áreas residências e comerciais, no qual são criados jardins internos ou externos" (PAIVA \& NÉRI, 2004).

Considerando que jardins, hortas e canteiros constituem espaços organizados com múltiplas funções: educacional, científica, social, ecológica e estética, dentre outras (ROCHA \& CAVALLEIRO, 2001), a implantação de jardim vertical e horta de plantas ornamentais e medicinais em escolas pode ser uma forma divertida, prazerosa e descontraída de abordagem a assuntos como a reutilização de materiais descartáveis, a utilização das plantas para fins medicinais, ao uso 
sustentável dos recursos naturais para fins comerciais, a importância de se manter o equilíbrio ecológico para a continuidade da vida do planeta, e entre outras coisas.

Uma forma inovadora de micropaisagismo que está sendo muito utilizada no Brasil é o "jardim vertical", uma técnica que inicialmente se especializava na elaboração de projetos que utilizavam as paredes nuas de prédios e residências, e por isso está relacionado com o conceito de sustentabilidade. Historicamente, o primeiro jardim vertical foram os jardins suspensos da Babilônia, mas apenas recentemente este conceito de paisagismo explodiu em consonância com 0 crescimento da consciência verde em todo o mundo. (CLARO, 2013). A ideia de fazer o jardim vertical a partir de garrafas pet no Brasil partiu do arquiteto Marcelo Rosenbaum, como forma de contribuir para o aproveitamento de materiais descartáveis que deixam de ser descartados, a ser implantado em locais que não dispões de espaços para jardins. (CLARO, 2013).

Deste modo, o jardim vertical de garrafas pet e uma horta tem se mostrado muito versátil em suas utilidades, pois além de enfeitar o local onde é instalado, ele também pode ser um local produtivo, podendo ser utilizado para o cultivo de plantas medicinais ou condimentares. Com um horta, é possível os alunos acompanharem vários ciclos, desde a compostagem e plantio até colheita, além do jardim, com o uso das garrafas pet, o ciclo da reciclagem (FERREIRA, 2018).

Partindo de sua versatilidade, surgiu a ideia de testá-lo como ferramenta metodológica de ensino na Educação Ambiental, como proposta de flexibilização curricular, visando um ensino de qualidade, por meio da utilização de uma metodologia alternativa. Na imensa abrangência ambiental, o homem se torna o principal agente de ações de transformação, conceituação e criação de métodos e ideologias, que aplicadas no seu cotidiano podem induzir a uma mudança de atitude no uso e preservação das riquezas naturais do planeta. O projeto da implantação do jardim vertical e horta de plantas ornamentais e medicinais em escolas de Ituiutaba e região foi pensado com a intenção de aproximar os alunos com as questões ambientais, promover a tomada de consciência acerca da manutenção dos recursos naturais e o respeito ao meio ambiente, na promoção do bem-estar, assim como socializar o conhecimento de cada um sobre as plantas ornamentais e medicinais 
que foram cultivadas, suas histórias além dos usos destas no meio científico e no cotidiano da população.

Objetivou-se implantar jardim vertical e horta como ferramenta de educação ambiental com estudantes do ensino fundamental e perceber suas contribuições para o ensino e aprendizagem.

\section{MATERIAL E MÉTODOS}

A realização de oficinas educativas serviu como ferramenta de educação ambiental em uma escola de ensino fundamental I localizada no município de Ituiutaba - MG. Foram abordados temas como a reutilização de resíduos inorgânicos, aproveitamento de resíduos orgânicos, plantas ornamentais e medicinais, condições para o plantio de mudas, rega, adubação, horta e jardim vertical. A metodologia utilizada consistiu na metodologia dos Três Momentos Pedagógicos onde se realizou as três etapas: Problematização Inicial (PI) através da exposição de vídeos e slides do problema do descarte incorreto dos resíduos; Organização do Conhecimento (OC) com o objetivo de se realizar a apresentação formal dos conteúdos estudados; Aplicação do Conhecimento (AC) com atividades práticas relacionadas diretamente com a situação problema.

As atividades práticas foram organizadas em quatro oficinas de forma que os alunos passassem por cada uma destas oficinas conhecendo, entendendo e aplicando os conceitos aprendidos em sala de aula. As atividades foram divididas em quatro oficinas: Oficina 1: Trabalhando Conceitos: Lixo, resíduos e 3R's; Oficina 2: Plantas Medicinais, Ornamentais e Hortaliças e sistemas de plantio; Oficina 3: Compostagem, Adubação e Rega; Oficina 4: Jardim e Horta Vertical. Em todas estas etapas foi utilizado como ferramenta didática os três momentos pedagógicos.

Oficina 1 - Trabalhando Conceitos Reduzir, Reutilizar e Reciclar: (PI): exposição de vídeos, slides do problema do descarte incorreto dos resíduos. (OC): Apresentação formal do conteúdo:-Conceito de lixo, perigos que o lixo oferece, tipos de lixo, destinação dada ao lixo doméstico, 3R's, coleta seletiva. (AC): Situação problema, proposta em forma de história em quadrinhos, para os alunos resolverem em forma de redação. 
Oficina 2 - Plantas Medicinais, Ornamentais e Hortaliças e sistemas de plantio: (PI): Apresentação de exemplares de cada grupo de plantas (ornamental, medicinal e hortaliça), questionar com os alunos sobre as diferenças e/ou semelhanças entre cada exemplar e sobre o conhecimento deles a respeito do que são plantas ornamentais, medicinais ou hortaliças, questionamentos sobre a importância das plantas na vida das pessoas e do planeta. (OC): apresentação formal do conteúdo através da definição de um conceito de plantas ornamentais, medicinais, hortaliças, fisiologia e morfologia, plantio, além de seus usos, importância das plantas na fabricação de medicamentos, na produção de alimentos e da relação da vegetação com a erosão, produção de oxigênio, alimento. (AC): Foi realizada a escolha das plantas a serem usadas no jardim vertical e horta: discutir o porquê de cada escolha, com base na fisiologia de cada espécie além do plantio das sementes e /ou produção das mudas que serão utilizadas na horta e no jardim vertical.

Oficina 3 - Compostagem, Adubação e Rega: (PI): Foram realizados questionamentos acerca de adubação, compostagem e rega/irrigação de hortas e jardins. (OC): Apresentação formal do conteúdo através da exposição dos conceitos de compostagem, adubação e rega, mostrando como são realizados e a importância de cada um destes para um bom desenvolvimento das plantas. (AC): Preparo dos substratos; manutenção das mudas.

Oficina 4 - Jardim Vertical e Horta: (PI): Definição pelos alunos do que é horta, jardim e jardim vertical. Realização de perguntas acerca de porquê fazer uma horta, porque fazer um jardim/vertical e se é possível fazer uma horta vertical, se sim, como seria possível implantá-lo na escola; (OC): Apresentação formal do conteúdo com o Conceito de horta, jardim e jardim vertical, importância de cada um destes e como criá-los e mantê-los. (AC): Implantação do jardim vertical e horta.

\section{RESULTADOS E DISCUSSÃO}

Foram realizadas melhorias no ambiente externo da escola em função da implantação do jardim e horta vertical de forma que o ambiente fosse mais propício aos processos de ensino e de aprendizagem. Para que estas melhorias fossem realizadas foram realizadas reuniões com a diretoria e parte do corpo docente da 
escola a fim de se definir os principais pontos a serem melhorados, os procedimentos adotados e de que forma seriam realizados estes procedimentos. Após a reunião teve início a realização das oficinas e o preparo dos materiais necessários para a realização das atividades. Os benefícios de um jardim suspenso e com pneus reutilizados são inúmeros, pois além de auxiliar na preservação do meio ambiente, beneficia na estética do espaço, além de estimular os alunos a serem cidadãos conscientes (VENTURA et al., 2018).

A primeira oficina realizada, o eixo principal girou em torno dos 3R's (reduzir, reutilizar e reciclar) os discentes tiveram um primeiro contato com as atividades (Figura 01) que seriam realizadas no projeto além de auxiliarem na formação de um conceito de lixo, resíduo e rejeitos e tiveram contato com os conceitos apresentados pelos integrantes do projeto de 3R's e da sua importância para a preservação do meio ambiente e do consumo consciente por parte de toda a sociedade.

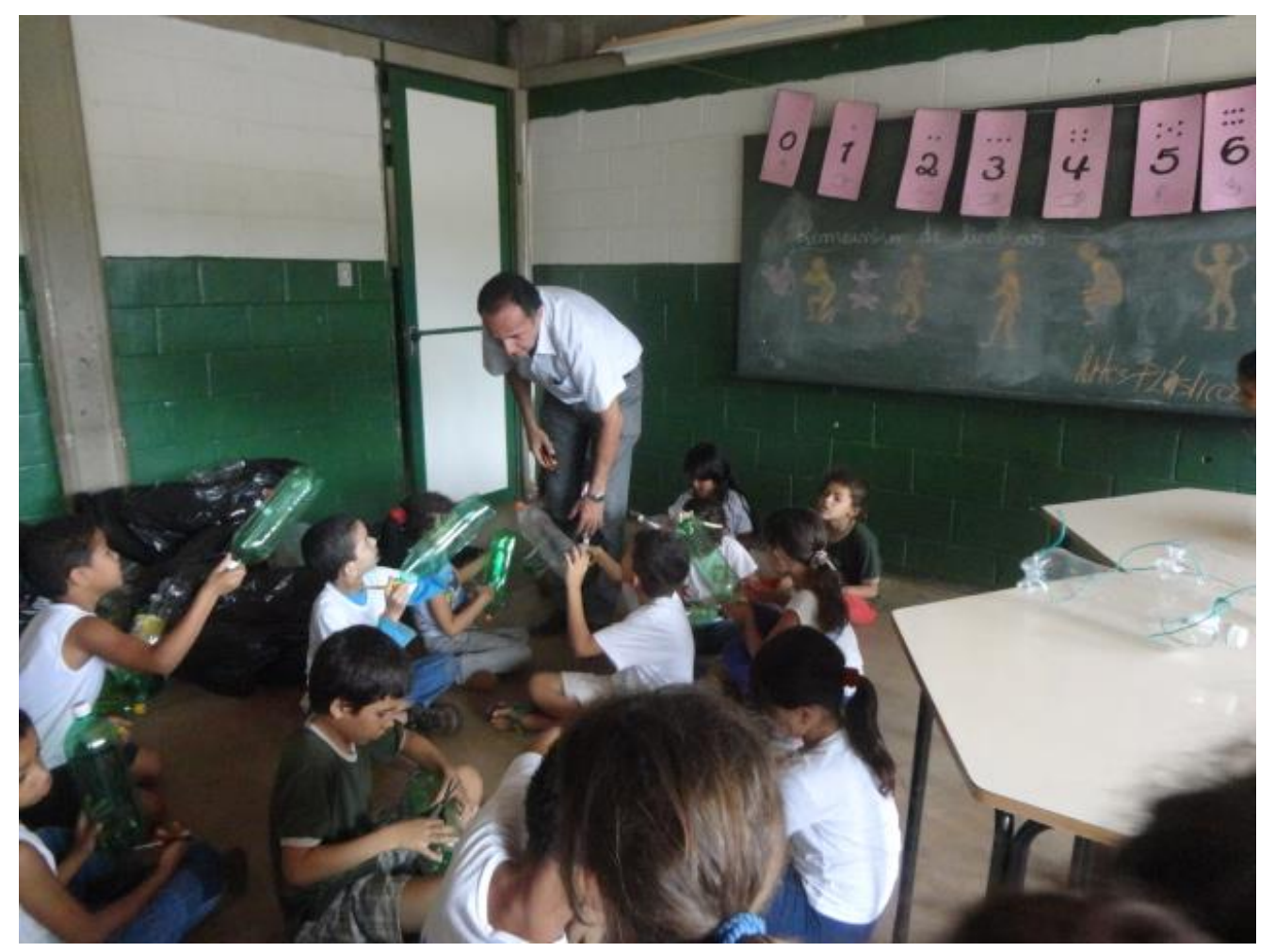

Figura 01. Os alunos iniciando as primeiras atividades do projeto, bem como recebendo as orientações visando a sua formação cidadã.

Fonte: Os autores. 
Durante as atividades realizadas na oficina 2 os alunos expuseram os seus conhecimentos com relação aos diferentes grupos de plantas que estavam sendo trabalhadas (ornamentais, medicinais e hortaliças), importância e as formas de utilização destas no cotidiano de todos (Figura 02). Foram realizadas atividades de forma que os alunos aprendessem de forma prática através da apresentação de exemplares dos diferentes grupos trabalhados em sala e das espécies que seriam cultivadas na horta e jardim vertical além de princípios básicos de morfologia, como por exemplo, a coloração e o formato das folhas. Os alunos, através de escolha direta escolheram as espécies que seriam cultivadas por todos na horta e no jardim vertical em função das formas de utilização e do formato e adaptação destas plantas ao ambiente de cultivo.

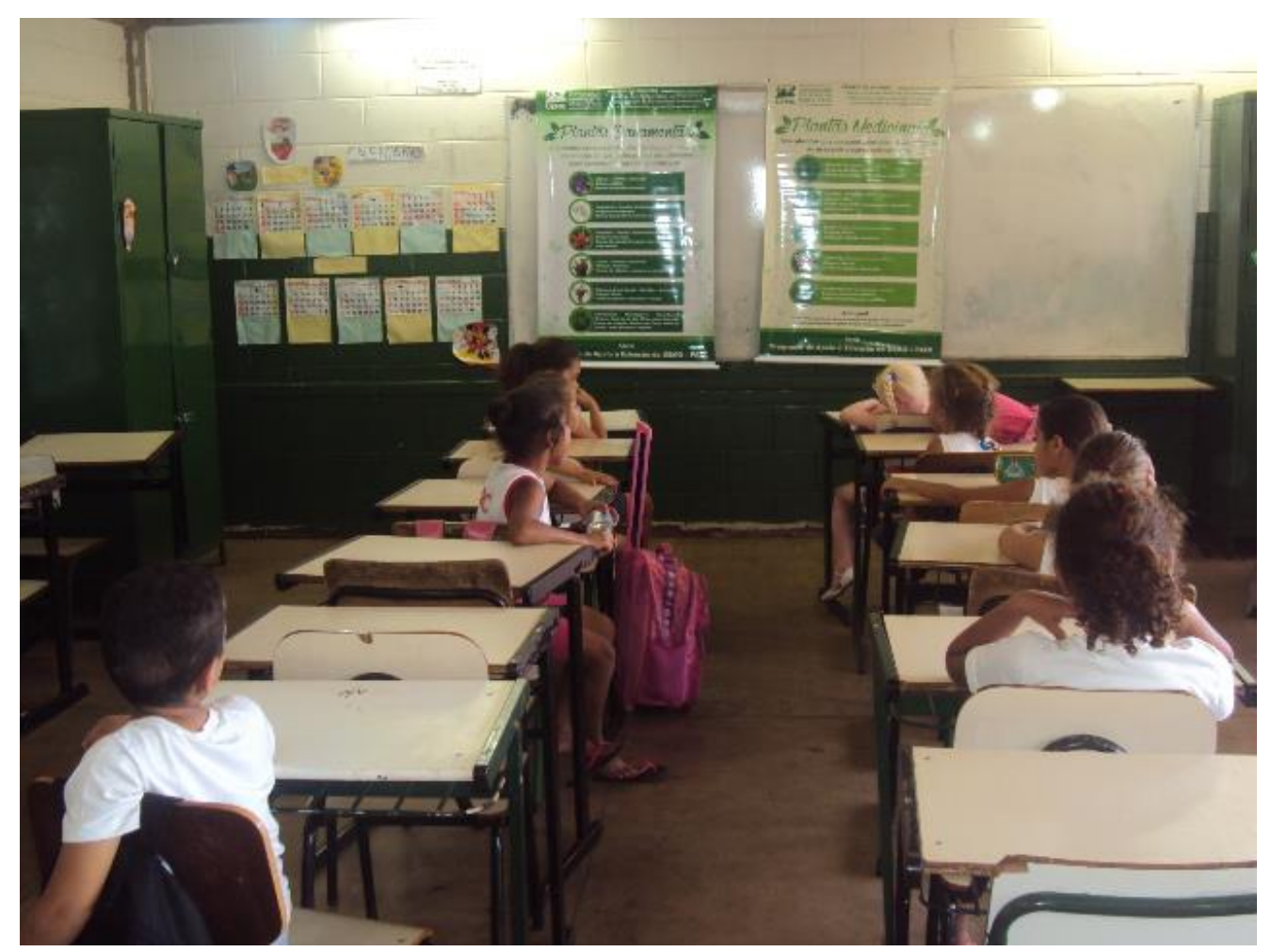

Figura 02. Atividades desenvolvidas dentro de sala com os alunos, onde foi apresentado diferentes grupos de plantas (ornamentais, medicinais e hortaliças), importância e as formas de utilização destas no cotidiano.

Fonte: Os autores.

$\mathrm{Na}$ oficina 3 , os alunos acompanharam todas as atividades relacionadas à compostagem dos resíduos orgânicos passíveis de compostagem produzidos na escola em função da produção das refeições servidas aos alunos. A oficina de compostagem teve a etapa teórica e prática, sendo etapas importantes para a Revista Científica Rural, Bagé-RS, volume21, №2, ano 2019

Submetido 23/08/2018. Aceito 24/09/2018. Doi: https://doi.org/10.30945/rcr-v21i2.2649 
compreensão da aprendizagem dos alunos. Sendo que foi relembrado e reforçado com os alunos o que consistia a compostagem, sendo a mistura de dejetos de animais e restos vegetais, para decomposição conjunta, sendo que, este resíduos virariam adubos para a plantas (SILVA, 2010).

Eles tiveram a oportunidade de conhecer os materiais que poderiam ou não passar pelo processo de compostagem, além de acompanharem o processo de produção do composto orgânico in loco, através de visitas ao local onde se encontrava a composteira e desta forma acompanhando todos os processos envolvidos, como por exemplo, a fase de abastecimento da composteira com material orgânico "úmido" como resto de vegetais e secos (podas de grama da própria escola e serragem), além dos processos de revolvimento e rega da composteira (Figura 03). Um trabalho bem semelhante foi realizado por acadêmicos no desenvolvimento de uma horta de temperos junto a uma comunidade escolar com alunos do ensino fundamental como descrito por Serafim et al. (2016), reforçando a importância de projetos neste sentido.

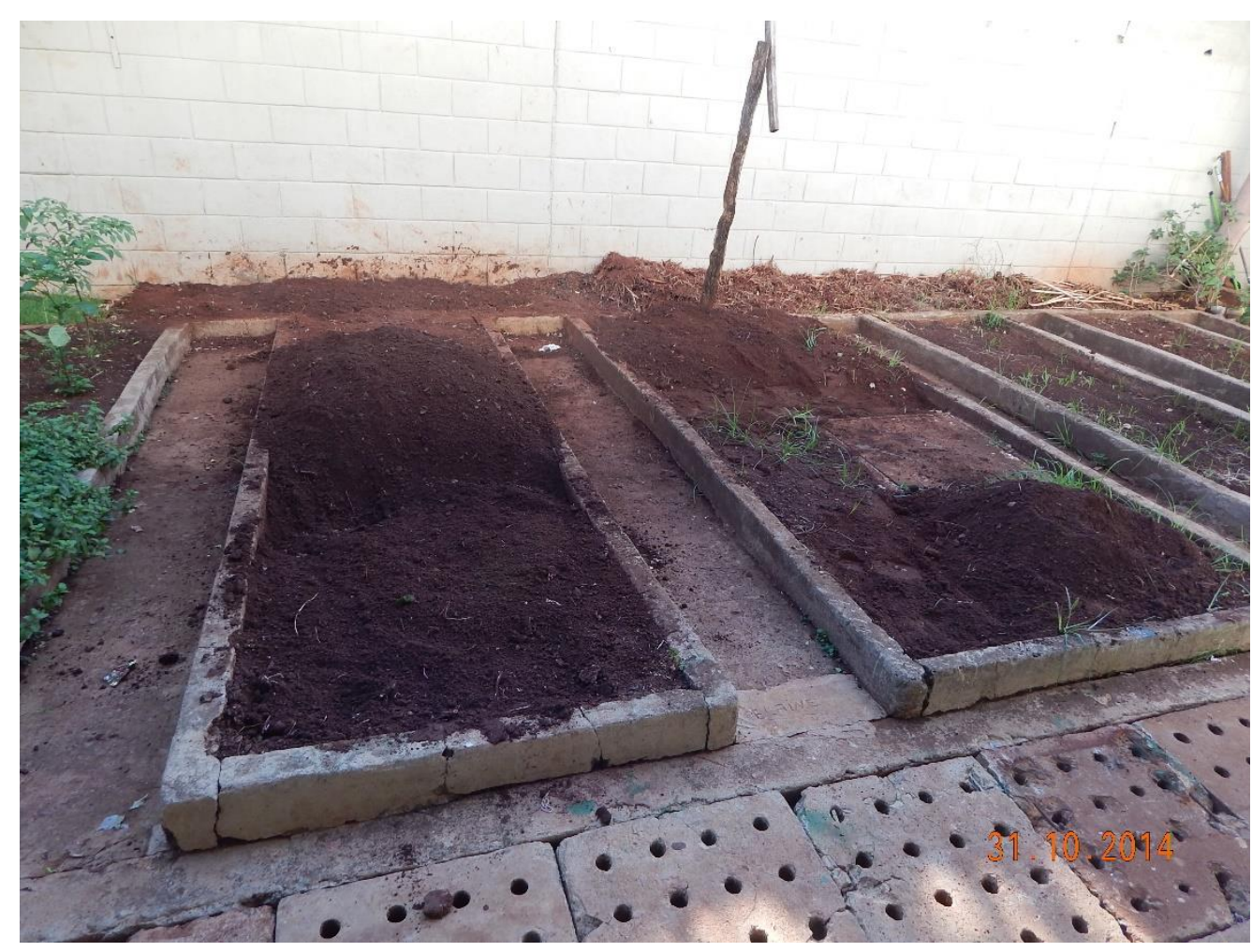

Figura 03. Composteiras produzidas na escola por meio dos alunos durante a execução das oficinas no projeto.

Fonte: Os autores. 
Durante os processos de montagem do jardim vertical (Oficina 4), os alunos foram incentivados a participarem de todos os processos de forma ativa. Os alunos realizaram a coleta das garrafas pet em suas próprias residências e as levaram para a escola com o objetivo de se realizar uma integração entre os conteúdos visto em sala de aula durante as atividades das oficinas e suas próprias residências e com isso fixarem o conceito de "reutilização". Após a coleta das garrafas pet estas foram selecionadas e lavadas e após a lavagem os alunos realizaram o recorte das garrafas dando a elas o formato de vaso. Após confeccionados os vasos, estes foram fixados na parede através de cordas de polietileno formando uma espécie de cortina. Os alunos também realizaram o preenchimento dos vasos confeccionados com o substrato preparado e as mudas (Figura 04), desta forma, tiveram um complemento do conhecimento previamente adquirido com relação à importância da utilização de adubos orgânicos, em especial do composto orgânico produzido, e da realização de adubações e de regas de maneira adequada evitando intoxicações por parte das plantas e danos ao meio ambiente como um todo.

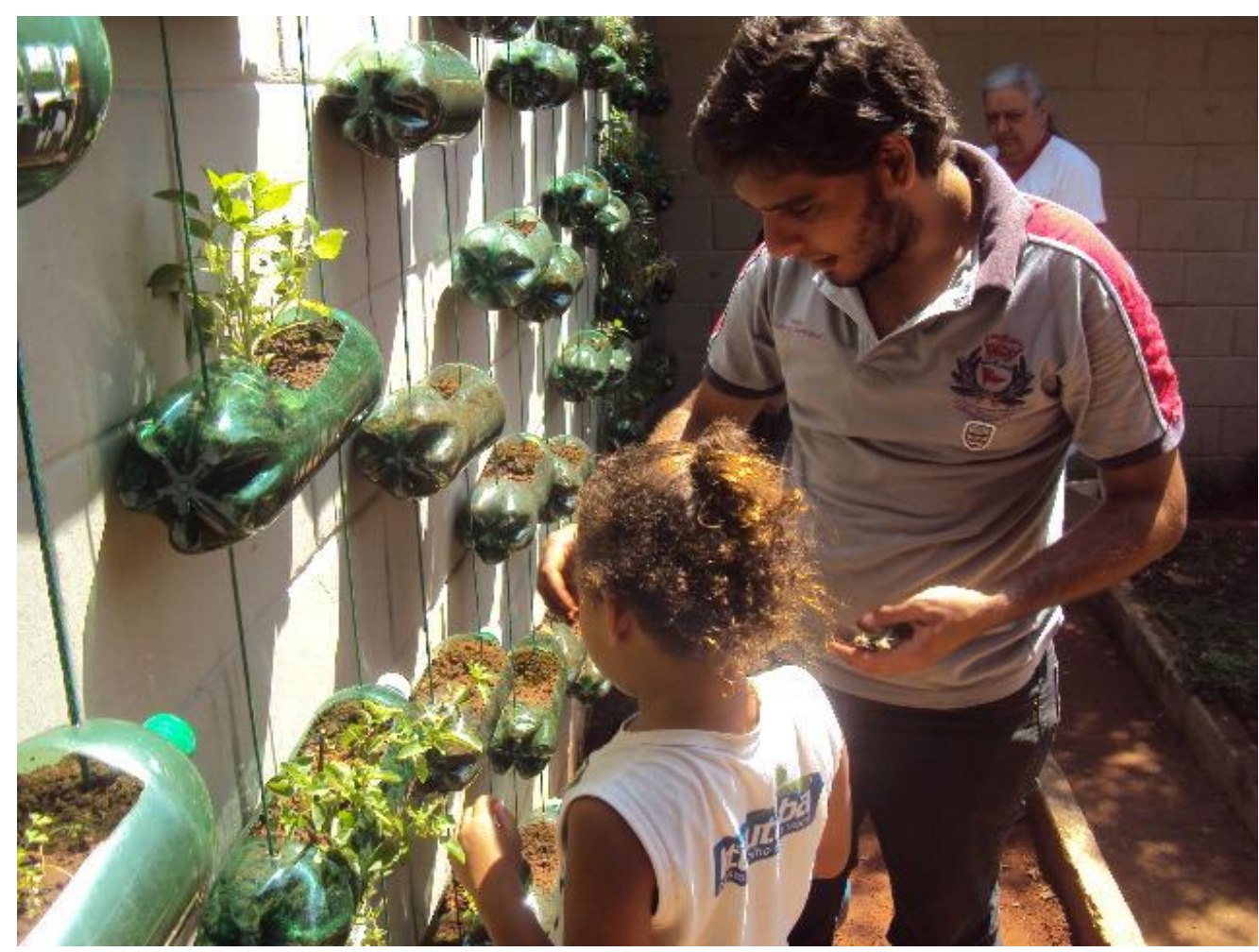

Figura 04 . Os alunos realizaram o preenchimento dos vasos confeccionados com o substrato preparado e em seguida, realizaram o plantio das mudas. 
Fonte: Os autores.

O resultado alcançado trouxe um ambiente mais bonito e agradável, bem como se tornou algo produtivo e um complemento na alimentação dos alunos (Figura 05), tais observações também foram relatadas por Ventura et al. (2018), na implantação de um jardim suspenso e com pneus com alunos de Colégio Militar na cidade de Goianésia, Goiás e Dias et al. (2017), na revitalização de um ambiente escolar e implantação de uma horta e jardim neste ambiente, na cidade de Ponta Porã, Mato Grosso do Sul.

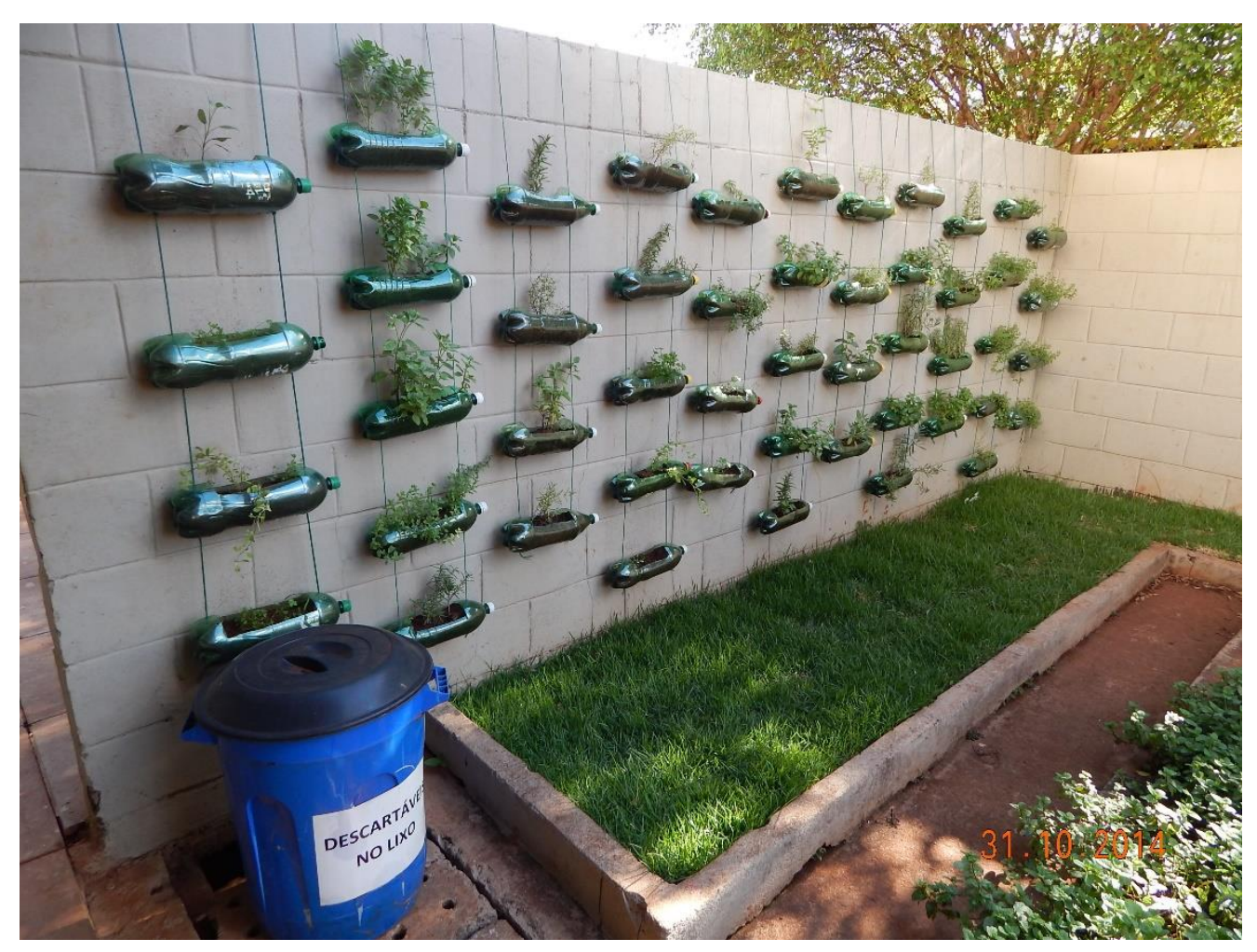

Figura 05. Jardim vertical construído com a utilização de garrafas pet pelos alunos.

Fonte: Os autores.

\section{CONSIDERAÇÕES FINAIS}

A conscientização dos alunos por meio da reciclagem é uma das estratégias muito eficientes para redução dos resíduos gerados, sendo a escola, o ambiente para geração de cidadãos conscientes e multiplicadores de atitudes e aliados junto ao meio ambiente.

A compostagem demonstrou um interação e participação dos alunos muito grande, sendo a curiosidade e a vontade de aprender e praticar, sendo os fatores que 
determinaram o sucesso dessa oficina. O acompanhamento do cultivo da horta e do jardim vertical atraiu bastante o interesse dos alunos, sendo assim, o objetivo alcançado pelo executores e professores da escola.

Foram realizadas melhorias no ambiente externo da escola em função da implantação do jardim vertical e horta de forma que o ambiente fosse mais agradável e mais bonito, além de aproximar os alunos ao meio ambiente, beneficiando com a conversão da sua produção em alimentos saudáveis.

O conhecimento construído a partir deste projeto permite que a comunidade crie seus jardins verticais e hortas para uso próprio ou com finalidade comercial, praticando o manejo adequado e respeitando o meio ambiente. É possível pontuar o jardim vertical nas escolas também pode ser utilizado como ferramenta de educação de outras disciplinas aplicando conceitos da interdisciplinaridade.

\section{REFERÊNCIAS BIBLIOGRÁFICAS}

CLARO, A. Jardins Verticais. Disponível em: < http://www.arq.ufsc.br/arq5661

/trabalhos_2013-1/jardins_verticais/jardins_verticais.pdf >. Acesso em: 10 mar 2014.

DIAS, S. A, ALCARÁS, J. D. C., ALVOS, E. Q., SANTOS, M. C. S., AMORIM, C. N., RONDELLI, K. G. S., \& POLIDO, C. A. REVITALIZANDO UMA ÁREA DO AMBIENTE ESCOLAR. Caderno Magsul de Ciências Biológicas, v. 5, n. 3, p. 15-17, 2017.

FERREIRA, K. B. A horta escolar como método de ensino e prática da Educação Ambiental. 2018. 16 f., (Trabalho de Conclusão de Curso de Pós-graduação lato sensu em Educação Ambiental - Instituto Federal de Educação, Ciência e Tecnologia Fluminense - campus Campos Centro), Campos dos Goytacazes - RJ, 2018.

PAIVA, P. D. O.; NÉRI, F. C. S. Micropaisagismo. In.: PAIVA, P. D. O. Paisagismo II: Macro e Micropaisagismo. Lavras: UFLA/FAEPE, 2004.

ROCHA, Y. T; CAVALHEIRO, F. Aspectos históricos do Jardim Botânico de São Paulo. Rev. bras. Bot., São Paulo, v. 24, n. 4, p. 577-586. DOI: 10.1590/S010084042001000500013 
VENTURA, M. V. A., BESSA, M. M., ALVES, L. S., \& COSTA, E. M. Implantação e benefícios de um jardim suspenso e com pneus em um Colégio Militar em GoianésiaGO. GLOBAL SCIENCE AND TECHNOLOGY, v. 11, n. 1, p. 41-48, 2018.

SILVA, H. R. S. Hortaliças Orgânicas: produção orgânica de hortaliças de raízes, tubérculos e rizomas. Coleção Senar 117; 2ํed., Brasília, 2010.

SERAFIM, Â. M., OLIVEIRA, B. R., CARVALHO, L. S., SILVA, F. D. S., \& PONTES, U. M. F. PIBID CIÊNCIAS BIOLÓGICAS NO PROCESSO DE ENSINO E APRENDIZAGEM: COMPOSTAGEM CONCEITO E PRÁTICA. In: Anais do Congresso de Ensino, Pesquisa e Extensão da UEG (CEPE)(ISSN 2447-8687), v. 3, 2016. 